\title{
Ute Kalender
}

\section{Zählen versus Erzählen? Gedanken zu Digitalisierung und Bildung}

„Gebildete Subjektivität kann nie gezählt, sie kann nur erzählt werden!“”so ein noch immer weit verbreitetes Credo vieler Geisteswissenschaftler^innen, geht es um die Digitalisierung der Lehre, der eigenen Wissensbestände, ja der Bildung im Allgemeinen. Ausgedrückt wird damit ein tiefes Misstrauen gegenüber einer Politik der Zahl, hier verstanden als das Faktum und das Versprechen, immer mehr soziale Milieus inklusive der Bildung für algorithmisches Regieren zu öffnen, zu erschließen und zu durchdringen (Alonso, Star 1987; Doneda, Almeida 2016).

Oft imaginiert das kritische Credo ein der Digitalisierung vorgängiges, ungeteiltes, unentfremdetes Bildungs-Subjekt, mal mehr, mal weniger ausgesprochen. Es ist ein Bildungs-Subjekt das jenseits seines Ideals nie existiert hat, dennoch aber dem digital geteilten Bildungssubjekt entgegengestellt wird. Es werde in der Digitalisierung entwirklicht, entsinnlicht, manipuliert, vor allem aber ökonomisiert. Sieht man sich aber die Erfahrungswelten jener an, die in und mit der Digitalisierung leben, lässt sich ein solcher Einspruch nicht halten. Erfahrung ist kein unproblematischer, nie ein unschuldiger Begriff. Dennoch: viele digital Vermessene sagen, dass das Digitale für sie bedeutet, endlich einmal ganz wahrgenommen zu werden, endlich als sie selbst anerkannt zu werden. Transgender-Jugendliche erfahren erst im Internet, dass es außer Ihnen noch andere gibt, die sich ähnlich fremd in der Schule, auf dem Sportplatz und in der eigenen Familie fühlen (Erlick 2018). Teilnehmende von Gesundheitsstudien durchlaufen ein sechsstündiges, hochgradig digitalisiertes Forschungsprogramm und beschreiben das Studienzentrum im Gegensatz zur Hausarztpraxis als einen Ort, an dem sie als Mensch voll zur Geltung kommen (Kalender \& Holmberg 2019).

Als eine kritische Gegenpraxis gilt das digitale Detoxen - die Medienenthaltsamkeit. Von mir selbst gern und genussvoll praktiziert, wird digitales Detoxen auch von Lehrenden und Lernenden regelmäßig als angemessene Haltung in digitalen Zeiten angepriesen. Im Grunde ist die Forderung des Medienverzichts aber ein Mittelschichtsmantra, eine kritische Bekundung eben jener, die über die Mittel der Digitalisierung verfügen, daran teilhaben, bereits Teil - Geteilte - sind (Avanessian abger. 
2019) und die meist mit dem sogenannten Globalen Norden assoziiert werden.

Eine solche politische Praxis provoziert geradezu den Einspruch jener, die in Zonen des globalen Südens leben. Oder die Gegenrede befreundeter Berliner Künstler`innen, die Monate auf ein iPhone sparen, den Rechner nicht reparieren lassen können, kein Geld für ein neues Ladekabel haben. Oder den Einspruch jenes Geflüchteten, der sich in seiner Unterkunft umgebracht hat, weil sein Smartphone kaputt ging und er so nicht länger Kontakt zu seiner Familie halten konnte. Oder das Unbehagen einer Frau nach einem langen Workshop-Wochenende, das zu digitaler Enthaltsamkeit aufgefordert hatte.

Digitales Detoxen ist eine Haltung, die an den großen Fragen der Digitalisierung vorbeigeht. Zu durchdenken wäre eher, um Impulse aus einem vorab der Klausur zirkulierten Pitch aufzunehmen: Mit welchen ausgrenzenden Stadtpolitiken geht die Errichtung eines Google Campus einher? Wer kann sich leisten, in der Umgebung zu wohnen? Wer muss wegziehen? Wen adressiert der Google Campus als ideales Bildungssubjekt? Die Diversen zwar, aber immer die kognitiv Starken? Auf welchen falschen Diversity-Vorstellungen basieren die Bildungspolitiken Googles? Welche neuen Formen des Datenkolonialismus (Couldry \& Mejias 2019), impliziert die Digitalisierung der Bildung? Wird der LernAlgorithmus verbessert? Oder fließt der Gewinn an die Lernenden und Lehrenden in den Institutionen zurück, die Inhalte en masse und unbezahlt bereitstellen - oder anders ausgedrückt: ohne deren flüchtigen, ephemeren Praktiken, ohne deren affektive, feminin codierte Arbeit keine Plattform je existieren kann. Wer verfügt schließlich über die Ressourcen, um zu einem digitalen Bildungssubjekt werden zu können? So bindet Corinna Schmechel in ihrer feinkonturierten, empirischen Analyse von Geschlechtersubjekten der Quantified-Self-Bewegung die Debatte um digitale Selbstvermessung an Fragen von gesellschaftlicher Ungleichheit in der Sorgearbeitsverteilung. Die Sportsoziologin stellt Aussagen von Frauen aus Onlineforen in den Mittelpunkt, die sagen, dass sie gern minutiös jede Körperregung, jede Gewohnheit und jedes Gefühl protokollieren, sich zeitintensiv das technische Know-how aneignen und mit Gleichgesinnten austauschen würden, aber drei Kinder hätten und ihr weniges Geld in der BioCompany und ihre knappe Zeit beim selbstgekochten Essen am Herd ließen (Schmechel 2016).

Schließen möchte ich mit der Imagination neuer Ästhetiken der Existenz, wie sie auch der Abendvortrag von Sara Lisa Vogl auf der Dießener Klausur anriss, aber auch der momentane Glitch- oder 
Xenofeminismus (Hester 2018; Russel 2018) sowie die feministischen Black Code Studies formulieren (z.B. Wade 2017). Diese bei Studierenden und im Kunstfeld äußerst beliebten Interventionen lehnen einen digitalen Dualismus ab - also die Annahme, dass On- und Offline zwei getrennte Welten sind. Sie sehen im digitalen Raum immer auch neue Potentiale, affektive Transformationsräume, das heißt Räume, wo Hautpigmentierung keine Basis für Teilhabe ist, wo neue Körperpraktiken ausprobiert werden können. Solche Beiträge erinnern auch an Vordenker des Digitalen wie Félix Guattari, der bereits 1987 in die Drei Ökologien nicht nur im Medium der Literatur sondern auch im Digitalen neue Politikmöglichkeiten sah, wenn er formulierte: „Künftig wird es an der Tagesordnung sein, ,futuristische und ,konstruktivistische“ Virtualitätsfelder frei zu schalten“ (Guattari 1994, 28). Rückgebunden an die Frage der Bildung heißt das: Für eine akademische Karriere ist neben Wissen, Wollen und Begabung ebenfalls ein akademischer Habitus, eine spezifische Körperperformanz wichtig. Eine Selbstgewissheit beim Sprechen, eine moderate, keine überbordende, exzessive Körperlichkeit. Wenn Digitalisierung der Bildung eine relative Entkörperlichung ist, weil Bildungsprozesse zunehmend in den digitalen Raum verlagert werden, kann das auch eine Unterminierung von Klasse bedeuten - also das Muss, einen spezifischen Körper für eine akademische Karriere vorzuweisen. Denn im virtuellen Raum können Studierende mit einem Hintergrund in Arbeiterfamilien, aber auch lesbische, transgender oder schwarze Studierende, schüchterne Studierende, die manchmal nur zufällig etwas, meist gar nichts sagen, möglicherweise freier agieren. Schließlich kann Entkörperlichung auch bedeuten, weniger pendeln zu müssen. Eine Freundin im Rollstuhl, die mittlerweile Professorin für Disability Studies ist, unterstreicht in Gesprächen zwar immer wieder, dass nicht Digitalisierung, sondern Armut und Behinderung das dringlichste Thema der Disability Studies ist, dass statt Handys auszuteilen, Städte anders gebaut werden müssen, begrüßt aber diese ,bedingte' Entkörperlichung. Denn für sie ist das Pendeln von Berlin in eine baden-württembergische Stadt noch einmal kräftezehrender als für körperlich Nicht-Behinderte. Und Digitalisierung bedeutet dann eine Erhöhung auch der Mobilität der Lehrenden und nicht nur der Studierenden. 


\section{Referenzen}

Avanessian, Armen: Wir haben keinen positiven Zukunftsbegriff mehr. Armen Avanessioan im Interview. Geführt von Christoph Koch. In: brand Eins. Online: https://www.brandeins.de/magazine/brand-eins-wirtschafts magazin/2018/geduld/armen-avanessian-interview-wir-haben-keinen-po sitiven-zukunftsbegriff-mehr [abgerufen: 10. September 2019].

Alonso, William, Star, Paul (Hg.): The Politics of Numbers. Population of the United States in the 1980s: A Census Monograph Series. New York 1987.

Couldry, Nick, Mejias, Ulises: Data Colonialism: Rethinking Big Data's Relation to the Contemporary Subject. In: Television \& New Media 20,4 (2019), S. 1-14, Online: https://doi.org/10.1177\%2F1527476418796632 [abgerufen: 10. September 2019].

Doneda, Danilo, Virgilio Almeida: What Is Algorithm Governance? In: IEEE Internet Computing, (Juli 2016), S. 60-62.

Erlick, Eli: „Trans Youth Activism on the Internet. In: Frontiers 39,1 (2018), S. $73-92$.

Guattari, Felix: Die drei Ökologien. Hg. von Peter Engelmann. Wien 1994, S. 11 50.

Hester, Helen: Xenofemimism. Cambridge 2018, S. 70-139.

Russel, Legacy: Glitch Feminism: An Interview with Legacy Russell. Von Russell Bennetts (21. Februar 2018), Online: https://www.berfrois.com/ 2018/02/glitch-feminism-an-interview-with-legacy-russell/ [abgerufen: 10. September 2019].

Kalender, Ute, Christine Holmberg: Zukünftige Datendoppel. Digitale Körpervermessungsgeräte in Kohortenstudien. In: Nils B. Heyen, Sascha Dickel, Anne Brünninghaus (Hg.): Personal Health Science. Heidelberg u.a. 2019, S. 91-106.

Schmechel, Corinna: „Der vermessene Mann?“ Vergeschlechtlichungsprozesse in und durch Praktiken der Selbstvermessung. In: Stefanie Duttweiler, Robert Gugutzer, Jan-Hendrik Passoth, Jörg Strübing (Hg.). Leben nach Zahlen? Selbstracking als Optimierungsprojekt? Bielefeld 2016, S. 141-161.

Wade, Ashleigh Greene, New Genres of Being Human: World Making through Viral Blackness. In: The Black Scholar, 47,3 (2017), S. 33-44. 
X Molíales Detosing als
Mittelsulidutsmantor

$\rightarrow$ Datenkolonialismus?

X Sprache als unveränderte

Grundlage anch der Dipitatisieray

$\rightarrow$ Digitalisierang der Sprache

$$
\text { ats Ubjent und Methode }
$$

$\rightarrow$ maschineller Sprachgebrauch Google Duplex

$\rightarrow$ Sprahalitwicklusing mid Alexa fuhil zu Spractiovandel, we then? $X$ Aufmerksamkeif fir. Aufmerksambat $\rightarrow$ Deep work

$\rightarrow$ Eipene Lösungen enturickeln

$\rightarrow$ Social computing

$w_{a}$ 
